\title{
A framework for e-commerce: its evaluation
}

\author{
A. Zailani \& M. Yazid \\ Department of Computer Science, \\ University College of Science and Technology, Malaysia
}

\begin{abstract}
E-commerce is an important element in the manufacturing industry such as MODENAS for them to participate in the worldwide markets globalization. However, determining a right framework for e-commerce solutions and evaluating its potential for success is a major challenge. Most of the frameworks are quite general and usually depend on the country or organizational needs. At the same time, the significant studies of its contribution to the organization are not properly addressed. As a result, the potential for success of the proposed framework is always questionable and need further explanation. Thus, this paper shows and evaluates the actual implementations of a framework called MODENAS Enterprise Web-Based Systems for E-commerce (MEWS) by using the Cost Benefit Analysis (CBA) and System Performance (SP) methods.

Keywords: e-commerce, potential for success, framework, implementation, evaluates, Enterprise Web-Based Systems.
\end{abstract}

\section{Introduction}

Internet technologies and application have grown more rapidly than anyone could have envisioned just five years ago, opening up new frontiers and interaction between consumers, business and trading partners [1]. Electronic commerce, or e-commerce, is a very broad term. The universal definition of ecommerce can be summarized as the buying and selling of goods and services via electronic means such as the Internet [10]. E-commerce uses computer technology to automate and streamline the complex processes in an effort to reduce operational costs and create greater profit margins [5]. The transactions undertaken in e-commerce usually involve buyers, suppliers, and information service providers (ISP). Usually, the technologies used for e-commerce includes electronic data interchange (EDI), e-mail, electronic bulletin board systems, electronic catalogs, electronic forms, finance and banking technologies, smart 
cards, fund transfer, and digital cash. Typically, there are four basic types of ecommerce relationship [2]: Business to business (B2B), Business to consumer (B2C), Administrator to business (B2A), and Administrator to citizen (C2A). EDI emerged as an important aid to transact business electronically in the 1980s. EDI means the computer-to-computer exchange of business transactions within large industrial communities or government. There are two major families of EDI standards, which are X12 and EDIFACT. Usually, EDI is made up of application programs, network software, and translation software [7]. Although EDI is an integral part of the digital economy, over the course of more than 20 years, only a small fraction of the business world adopted EDI [1].

Security in e-commerce is extremely crucial. There are various security technologies in place such as Public Key Infrastructure (PKI), Secure Socket Layer (SSL), Virtual Private Network (VPN), firewall and many more to overcome and mitigate the risks of transacting over the Web. PKI enables organizations to securely conduct their business on public networks by providing user authentication, non-repudiation, data confidentially, and data integrity [3]. The Secure Sockets Layer (SSL) is a commonly used protocol for managing the security of a message transmission on the Internet. SSL has recently been succeeded by Transport Layer Security (TLS), which is based on SSL. SSL uses a program layer located between the Internet's Hypertext Transfer Protocol (HTTP) and Transport Control Protocol (TCP) layers [4]. Virtual Private Network (VPN) is a new technology that allows secure remote access to a private network via a "privacy" tunnel installed within an existing infrastructure. These systems use encryption and other security mechanisms to ensure that only authorized users can access the network and that the data cannot be intercepted [9]. Instead of VPN and SSL, firewall is also playing an important role as a "stand guard" between a company's corporate network and the Internet. The firewall will inspect all communications passing between the Internet and the private network and either pass or drop the communications depending on how they match the programmed policy rules [6]. Instead of various security technologies for e-commerce, it is significant to ensure the e-commerce servers are always available for on-line transaction. This can be achieved by implementing the fault tolerant system architecture.

The following part discusses a framework and the practices of implementing e-commerce in this company. This framework will also cover redesign of the business model and introduces a scalable e-commerce solution at affordable cost. Some of the uncertainties and problems while developing and implementing the e-commerce system have been resolved through the MEWS framework. Thus, the idea and solution proposed is an important factor to be reviewed by this company in order to provide a competitive edge and better services to their business partners.

\section{Materials and methods}

MODENAS was established in 1996 and spearheads the technology transfer of motorcycle manufacturing to produce indigenous motorcycles. Kawasaki Heavy 
Industries (KHI) is the technology partner of MODENAS. Most of the company's operational activity involves with Information Technology, from production to sales and marketing. The details about the MEWS framework have been discussed in the "MODENAS Enterprise Web-based System (MEWS) Framework For E-commerce Solutions In MODENAS" [11]. The new business model can be illustrated as in Figure 1.

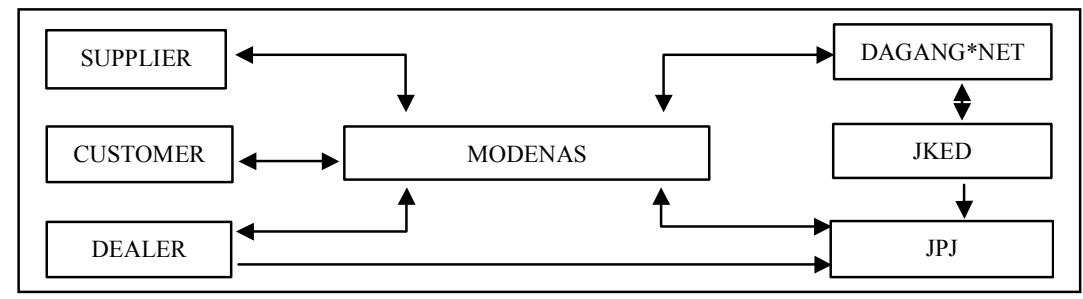

Figure 1: Overview of MEWS.

From Figure 1, the SNS entity has been removed and the dealer or supplier will have two ways of communication to MODENAS. An additional entity called "customer" is also included to show that customers are enabled to perform business dealings directly with MODENAS. Otherwise, the rest of the flow remains unchanged especially with regards to JKED. The detailed proposal for a MODENAS business model can be viewed in Figure 2. The discussion on the first e-commerce system at MODENAS called e-procurement will cover indirectly, Supply Chain Management (SCM). Basically, SCM is one of the areas applied by an e-commerce model [8].

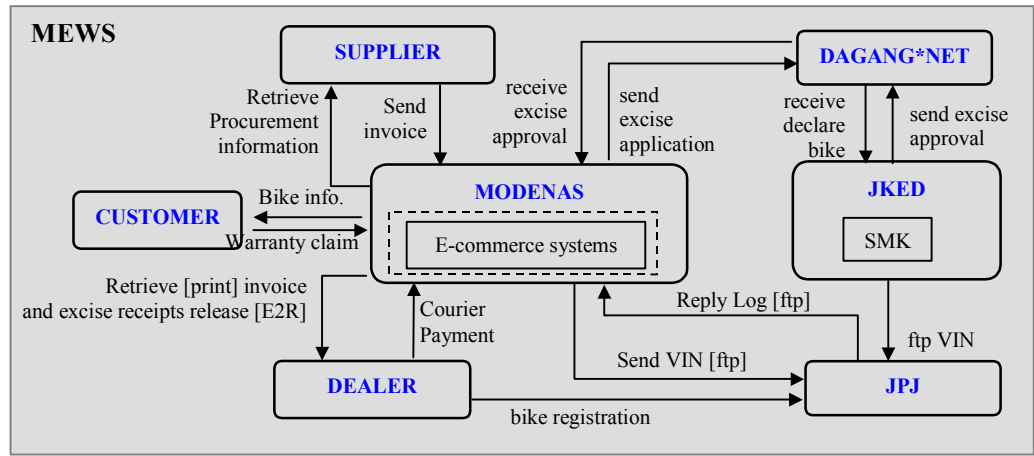

Figure 2: $\quad$ Detailed MEWS framework.

The e-procurement system (or EPS) was deployed by MODENAS in early 1998. It has been provided by Singapore Network Services (SNS) for publishing procurement information in MODENAS's Intranet. Basically, MODENAS sends procurement data in flat-file format to SNS. Once it is received, SNS will just publish all this information in the web page. Suppliers or vendors will then access their related information when they logon into the system. MODENAS 
will prepare the list of parts that have been ordered in the Material Resource Planning (MRP) system. Users are not required to printout the purchase order and manually send them to the supplier. Normally, by the end of the day, the procurement data in the predefined flat-file format will be generated and sent manually to SNS for publishing the following day. The supplier will notice any new purchase order from MODENAS by logging into the E-procurement system. They will then download the data into Microsoft Excel spreadsheet format for reference. SNS will charge them based on the item (parts) listed in the "purchase order" appearing in the Excel spreadsheet. Basically, this system has 7 modules that can be used by vendors, namely Purchase Order, Delivery Schedule, Receiving DO Report, P/O Data Inquiry, Outstanding P/O, Invoices Detail Summary and Account Payable Checklist. The second e-commerce system at MODENAS is Electronic Excise System (EES). Generally, this system will cover the electronic data interchange between MODENAS and Jabatan Kastam dan Eksais Diraja (JKED). The EES is based on a dedicated leased line "Extranet" connection provided by Dagang*Net Technologies Sdn Bhd, linking MODENAS with JKED and Jabatan Pengangkutan Jalan (JPJ). The system would facilitate the electronic submission and endorsement of Excise 7 document, and automation of excise duty payments, thus leading to online vehicle registration.

Table 1 illustrates the original cost for manually submitting Excise 7 forms to JKED. MODENAS has to spend about RM 101,962.26 per year for completing this exercise. Two categories of cost involved here are internal cost and external cost. The internal cost consists of materials and manpower used to complete cycle of Excise 7 distribution. At the same time, the company also has to reserve funds for paying overtime claims to JKED officers for handling Excise 7 forms belonging to MODENAS. These officers have to register and stamp approximately 650 excise 7 documents daily.

Table 1: $\quad$ Cost savings - manual submission.

\begin{tabular}{|c|c|c|c|}
\hline No & Items & Unit Cost & $\begin{array}{l}\text { Cost per annum } \\
\text { (250 days) }\end{array}$ \\
\hline 1 & $\begin{array}{l}\text { Paper Cost/Excise Form } \\
\text { (Production volume in } 2000-101,052 \\
\text { units) }\end{array}$ & $\begin{array}{l}15 \text { cents per copies, } 13 \text { copies per set, } \\
10 \text { motorcycles per copies }\end{array}$ & $19,705.14$ \\
\hline 2 & $\begin{array}{l}\text { Manual Processing Cost } \\
\text { - Delivery and Follow-up } \\
\text { - JKED Overtime }\end{array}$ & $\begin{array}{l}2.5 \text { hrs @ RM } 8.00 \text { per hour } \\
\text { RM } 300 \text { per month }\end{array}$ & $\begin{array}{l}5,000.00 \\
3,600.00\end{array}$ \\
\hline 3 & Staff Claim & $60 \mathrm{~km} @ 50$ cents per km, RM60 per day & $15,000.00$ \\
\hline 4 & $\begin{array}{l}\text { Consumable } \\
\text { - Toner ( } 18 \text { unit per annum ) } \\
\text { - Photostat ( } 140,569 \text { copies for } 2000 \text { ) }\end{array}$ & $\begin{array}{l}\text { RM } 130 \text { per unit } \\
5 \text { cents per copies }\end{array}$ & $\begin{array}{l}2,340.00 \\
7,028.45\end{array}$ \\
\hline 5 & Courier Charges ( 20 parcel per day ) & RM 4.73 per parcel & $23,650.00$ \\
\hline 6 & $\begin{array}{l}\text { Work re-allocation - } 3 \text { staffs } \\
\text { (Credit control and logistics dept) }\end{array}$ & RM 1500 per month & $24,000.00$ \\
\hline & Total Estimated & & $100,323.59$ \\
\hline
\end{tabular}

The figures shown in Table 1 come from internal system namely the Vehicle Management System (VMS). From 1996 to 2001, MODENAS delivered 
505,526 motorcycles in Malaysia. Figure 3 shows the total motorcycle production taken from 1996 to 2000 .

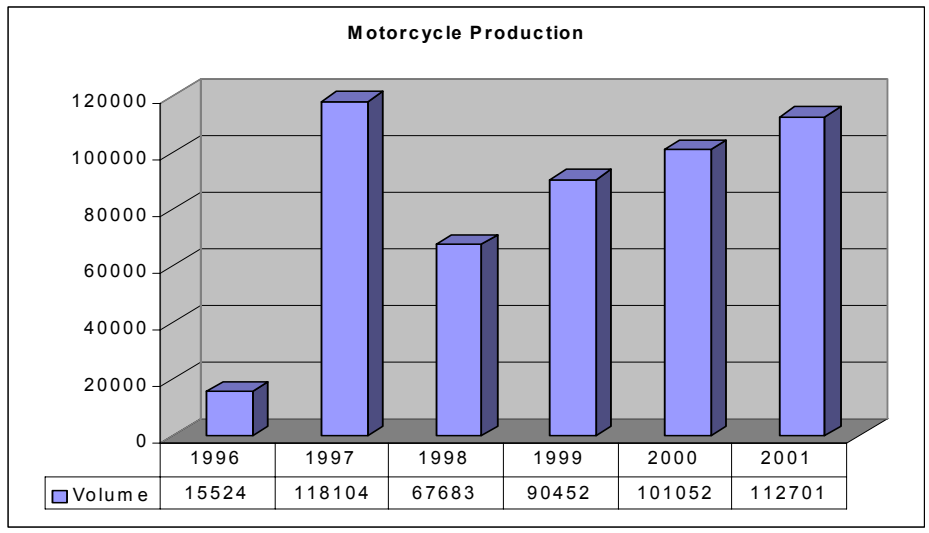

Figure 3: $\quad$ Motorcycle production.

Usually, a manual submission of Excise 7 forms takes not less than 4 days. Logistics officer will go to JKED at Sungai Petani (Kedah) or Seberang Jaya (Penang) for getting Excise 7 endorsements. After 5 years of operation, the best lead-time that MODENAS has experienced is about 3 days. The complete cycle time of manual submission of Excise 7 can be illustrated as in Figure 4.

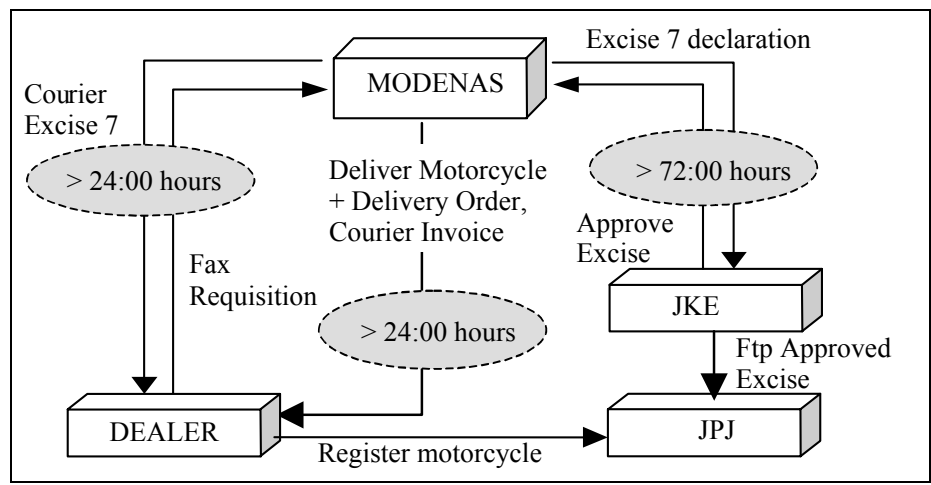

Figure 4: $\quad$ Manual excise 7 cycle times analysis.

\section{Results and discussion}

The part discuss overall performance analysis of selected E-commerce systems namely EES. This detailed analysis covers Cost Benefit Analysis (CBA) and System Performance (SP). The first part, CBA will show the advantages of EES in terms of reducing manpower and operational costs. The second part, SP will evaluate actual performance based on statistical information from EDSPLUS 
software. The purpose of a CBA is to promote efficient resource allocation through implementation of EES. This would result in a series of measurable benefits or costs extending for future years. The baseline for CBA is the original process. Basically, CBA can provide basic understanding to the committee whether to stop or proceed with this project at the initial stages. Besides identifying the considerable benefits, it also helps to determine the new costs and risks to the customer. The CBA is the best method to analysis the cost and benefits of a project in terms of money value. The CBA determines whether on balance the project is worthwhile. Based on Figure 3, the calculation of estimated cost from 1996 to 2000 while using manual Excise 7 submission is shown in Table 3. This calculation excludes year 1996 since the motorcycle sales volume was not significant $(15,534)$. At the same time, during 1996, the first delivery of motorcycles started in the last quarter of year 1996 (13 Sept 1996).

Table 2: $\quad$ Estimated cost 1996 to 2000.

\begin{tabular}{|l|l|c|}
\hline Item & \multicolumn{1}{|c|}{ Amount } \\
\hline Volume Production & $392,825 \quad *(0.15$ cents $* 13$ & $76,600.875$ \\
\hline - Paper Cost & $\begin{array}{l}392,8255^{*} \\
\text { copies / 10 motorcycle) }\end{array}$ & $322,473.80$ \\
$\begin{array}{l}\text { - Other Cost } \\
\text { (Excluded year 1996) }\end{array}$ & RM 80,618.45*4 years & \\
\hline TOTAL & \multicolumn{2}{|l|}{$399,074.675$} \\
\hline
\end{tabular}

Based on Table 3, MODENAS has to spend around RM 400,000 to ensure the complete cycle of Excise 7 distribution throughout Malaysia. Estimates of cost savings while using EES can be shown in Table 4. Most of the figures provided in this table are based on MODENAS internal cost and final external costs quoted by Dagang*Net Technologies Sdn Bhd (Dagang*Net). The data shown here is more for analysis and research purposes.

MODENAS only has to incur a one time cost of around RM 21,400 for initial setup including Dagang*Net charges and internal expenses until completing the EES project. The yearly operating cost based on estimated delivery volume is about RM 72,685.00. By comparing the original implementation against this new alternative, the company can reduce costs by RM $27,638.59$ or $27.55 \%$ yearly.

System performance is extremely crucial for any e-commerce applications. It is important to analyze the cycle-time to complete the e-commerce transactions. This method is a good mechanism to identify whether e-commerce implementation can speed up or slow down the entire processes. For the purpose of research, the author has selected one e-commerce application in MODENAS namely EES. As mentioned in an earlier chapter, EES facilitates the electronic submission of Excise 7 document between MODENAS and JKED. The dedicated leased line "extranet" connection provided by Dagang*Net Technologies, links MODENAS with JKED and JPJ. Dagang*Net will provide the box office for both organizations for message interchange purposes. MODENAS sends declaration messages in predefined format (EDIFACT 
format) to JKED box office everyday. JKED will then pickup this message and register into their system namely, Sistem Maklumat Kastam (SMK). Once the process is completed, JKED sends back the acknowledgement message to MODENAS post box office. MODENAS needs to pickup this message and upload it into EES. Credit Control officers will use the information from the acknowledgement message for preparing the Excise Receipt Release to be sent to the respective dealer.

Table 3: Cost savings - electronic submission.

\begin{tabular}{|c|c|c|c|}
\hline No & Items & $\begin{array}{c}\text { Estimated One } \\
\text { Time Cost }\end{array}$ & $\begin{array}{c}\text { Estimated } \\
\text { Operational Cost }\end{array}$ \\
\hline 1 & $\begin{array}{l}\text { Installation - One Time Cost } \\
\text { DAGANGNET STANDARD CHARGES } \\
\text { a. Translation and Communication Software } \\
\text { b. DagangNet Registration Fee } \\
\text { c. Message mapping and certification } \\
\text { MODEM ( } 2 \text { units ) } \\
\text { Project Management, Travelling \& Others } \\
\text { Total }\end{array}$ & $\begin{array}{c}5,000.00 \\
1,400.00 \\
3,500.00 \\
1,500.00 \\
10,000.00 \\
21,400.00\end{array}$ & \\
\hline 2 & $\begin{array}{l}\text { Operating Cost - Usage Charges } \\
\text { - RM } 0.70 \text { per KB. Normal message size is } 1.3 \mathrm{~KB} \\
\text { - Storage charges RM } 2 \text { after } 5 \text { days ( per KB, per day ) } \\
\text { - Estimated usage is } 450 \mathrm{~KB} \text { for } 400 \text { bikes } \\
\text { - Estimated delivery } 100,000 \text { per annum } \\
\text { Monthly Service Subscription Fee for Dial-up ( RM } 180 \\
\text { per month ) } \\
\text { Annual Renewable License Charges }\end{array}$ & & $\begin{array}{c}70,000.00 \\
2,160.00 \\
525.00\end{array}$ \\
\hline & Total Estimated & & $72,685.00$ \\
\hline
\end{tabular}

Based on the above scenario, the two major processes involved for performance-analysis purposes are:

- MODENAS to JKED

- MODENAS to DEALER

The performance analysis of the processes between Dealer to JPJ is not covered in this discussion. This process was briefly mentioned while discussing both of the major processes. Basically, the time frame to register MODENAS motorcycles depends on how fast the motorcycle records are registered into JPJ system. Figure 5 illustrates the response-time that was captured from ADS/PLUS message status starting from August 2001 until March 2002. ADS/PLUS is a software solution to translate incoming or outgoing messages into EDIFACT file format. This statistic can be used to analyze the lead-time between MODENAS and JKED. Based on the above graph, the average response-time from JKED to MODENAS is around one hour (58:59 minute) per messages. In short, all the motorcycles produced in MODENAS are ready with Excise 7 documents in less than one hour. A manual declaration of Excise 7 to JKED takes approximately 
72 hours (3 days) after submission. By implementing EES, MODENAS can speed up the declaration process up to 48 times better than by manual declaration.

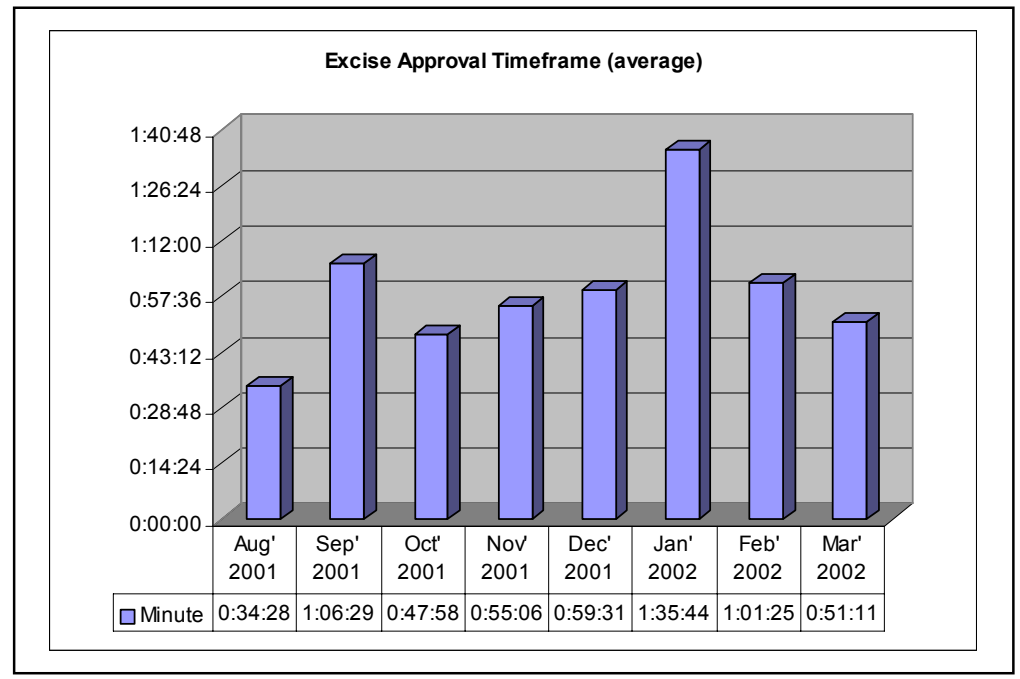

Figure 5: Excise 7 approval timeframe.

In terms of analyzing performance between MODENAS and its dealers, the statistical data was taken from EES users at Gurun (MODENAS HQ) and Shah Alam branch. Usually, the delivery of motorcycles to dealers takes about one day (excluding the northern region such as Kedah, Perlis and Penang). After dealers receive motorcycles together with Delivery Order documents, Credit Control would immediately courier invoices to them the following day for payment purposes. Dealers fill in all the information in the Excise Requisition form and courier this document together with cheques to Credit Control department whether at Gurun or at Shah Alam branch. Normally, they would also fax a copy of Excise Requisition to Credit Control department to allow Credit Control officers time to prepare Excise Receipt Release document early. Once a Credit Control officer receives an Excise Requisition form, they will key in the cheque information into EES "Generate Payment" screen. After completing this screen, he proceeds to "Generate Excise Release" screen in order to set-off that payment against selected invoices. The final stage is to print the Excise Receipt Release document and fax it back to the dealer. The average timeframe for completing this process is around 5 minutes at normal hours or 10 minutes at peak hours.

There are frequently cases where dealers fax and courier Excise Requisitions before receiving the physical Invoices. Usually, once they receive a Delivery Order $(\mathrm{D} / \mathrm{O})$, they can manually calculate the total amount due for that $\mathrm{D} / \mathrm{O}$ since they already know the price of each model of motorcycle. In this situation, the Credit Control office will immediately prepare the Excise Receipt Release and 
send to them for registration purposes. After implementing EES, the complete cycle time can be shown as in Figure 6.

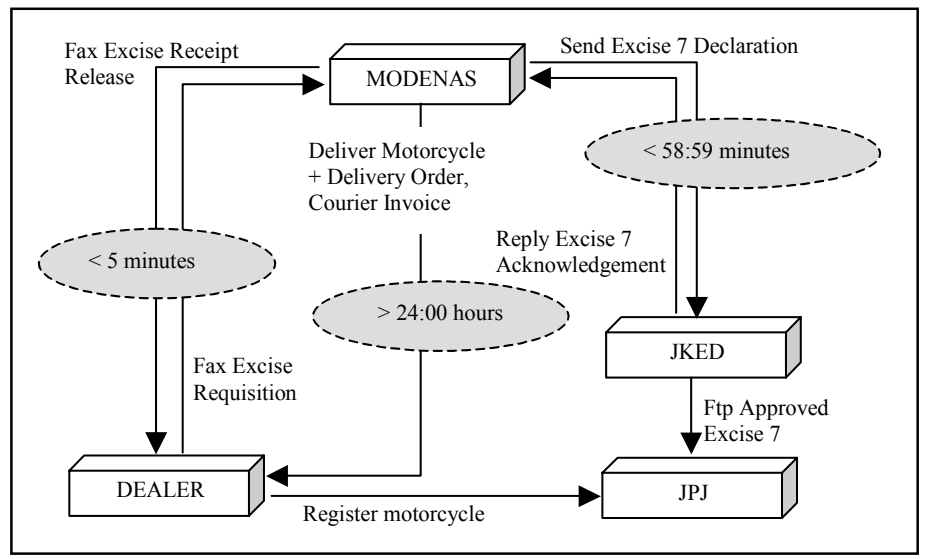

Figure 6: $\quad$ EES cycle times analysis.

JPJ will register any MODENAS motorcycle after receiving the motorcycle record from JKED. According to JKED, after successfully registering the motorcycle information into their system (SMK), they will proceed with the transfer of this record to JPJ using ftp (file transfer protocol). In short, after Excise 7 has been approved by JKED, within a few minutes, the motorcycle record is already available in the JPJ database. From Figure 3, after dealers receive their motorcycles, they have to wait 4 days before going to JPJ for registration. This is detrimental for customer satisfaction since buyers have to wait up to 4 days before they can receive their motorcycles. It is now different after implementing EES. As illustrated in Figure 4, once dealers receive motorcycles, they can immediately sell to customers and on the same day they can register it with JPJ.

\section{Conclusion}

In this paper, the MEWS framework has been evaluated in the motorcycle's manufacturing industry environment. The Cost Benefit Analysis (CBA) and System Performance (SP) have been done to evaluate its potential for success. Basically, the CBA determines the total investment needed and the benefits gained from this project. Based on the CBA, it shows that it is really beneficial, giving value added advantages by adopting the MEWS framework in the project. For SP, the measurable item used is time (minutes / hours / days). At this stage, it shows that the complete cycle of EES is significantly better then the original manual process. Based on the CBA and SP, it clearly shows that this framework is excellent and helps MODENAS to successfully implement and expand the Ecommerce solutions in the near future. 


\section{References}

[1] Barua, A., Andrew, B. and Yin, F., "Value and Productivity In The Internet Economy", Internet Watch May 2000: pp. $1-4$

[2] Chan C. and Swatman P.M.C. (1999) "E-Commerce Implementation in Australia: A Case Study Approach", Proc. Conf. 'CollECTeR'99' - 3rd Annual CollECTeR Conference on Electronic Commerce, Wellington, New Zealand, November 29.

[3] Gaya, C., "Public Key Infrastructure - A Brief Overview", SANS Institute. November 2000. Online. http://rr.sans.org/encryption/PKI.php

[4] Jenkins, G.P., and Wright, "Managing inflexibility Supply Chain", International Journal of Logistic Management, vol. 9, no. 2: pp. 83 - 90, 1998.

[5] Jonathan, D. and Bowers, R., Securing E-Business Applications and Communications. Florida, USA: Auerbach Publications, 2001.

[6] Matthew, S. and Charles, P., Firewalls 24 Seven, Alameda, CA, USA: Subex Inc, 2000.

[7] Sawyer, C., William, K. and Hutchison, E., Using Information Technology: A Practical Introduction To Computers \& Communications (Brief version), Irwin McGraw-Hill companies, Inc., USA, 1999.

[8] VeriSign White Paper: Encryption and Digital Certificates. Online http://www.verisign.com/whitepaper/enterprise/overview

[9] VPN. Online http://www.webopedia.com/TERM/V/VPN.html

[10] Warwick, F. and Micheal, S., Secure Electronic Commerce: Building The Infrastructure For Digital Signatures And Encryption. New Jersey, USA: Prentice Hall, Inc., 1997.

[11] Zailani Abdullah, Md Yazid Mohd Saman, Mustafa Mat Deris (2002), "MODENAS Enterprise Web-Based System (MEWS) for E-Commerce Solutions", The National Seminar of STSS, UiTM. vol 1:pp. 135 - 142 